\section{Remediation Technologies for the Removal of Arsenic from Water and Wastewater}

Arsenic currently threatens millions of people in West Bengal, Bangladesh, and Thailand, as a result of their exposure to contaminated groundwater (where concentrations may reach $0.06 \mathrm{mg} / \mathrm{L}$ to $1.86 \mathrm{mg} / \mathrm{L}$, a value far in excess of the World Health Organization [WHO] Maximum Permissible Levels). Major problems have also been identified in some areas of the USA, China, and South America.1,2 The WHO and the U.S. Environmental Protection Agency (EPA) recommended limit for arsenic in drinking water is currently $10 \mu \mathrm{g} / \mathrm{L} .^{3}$ It is not so much the difficulty of removing arsenic from water, as the extremely low levels to which it must be reduced to ensure safety, that presents the challenge to water treatment initiatives, especially in developing countries where the issues of cost and expertise often make "high-tech" solutions impractical.

Many extensive reviews of arsenic remediation technologies exist in the literature. However, there remains a need for a simplified and practical guide that condenses the available literature in a form that will allow informed decisions to be made. This project aims to produce a scientifically sound report that will at the same time inform and advise non-specialists on key aspects of arsenic remediation technologies. The report should ideally help people in arsenic affected areas by providing a practical and easy to follow guide, similar to the WHO guide for infectious agents in water.

The guide would advise people in these areas on what steps should be undertaken to mitigate the problem depending on local conditions, including initial arsenic concentrations, arsenic speciation, general water chemistry, and availability of materials and expertise, as well as cost.

The task group will critically evaluate remediation technologies and their possible uses under various conditions. The project will address the transferability of specific technologies that are currently associated with local conditions. As well as making positive recommendations, the work will attempt to predict hazards, complications, and possible failures that may arise from technology transfer between specific field conditions. The project will consider outcomes of remediation technologies in the wider context of overall water quality (e.g., microbiological contamination) rather than just arsenic contamination.
Analytical aspects (i.e., measurement of arsenic in water) are also important for the management of water supplies. Those who use technology to reduce arsenic levels in drinking water should be able to reliably measure and evaluate arsenic concentrations in their supplies. Given the need for relatively simple, but at the same time reliable, measurements, the guide will review and advise on the accuracy, reliability, and overall suitability of currently available field tests kits.

Headed by Hemda Garelick, the task group held their first meeting in January 2005, and the following contributions and tasks have been agreed upon:

1. Introduction-to provide a brief historic overview and comment on the nature and form of arsenic and its changing economic significance to society.

2. Arsenic Pollution Sources-to survey point sources (industrial, mining) and diffuse sources (geochemical, water supply) by categories: natural water (wells, hot springs), industrial (end of pipe), and mining/industrial (diffuse-either from past or current mining activities).

3. Chemical Behavior-to review processes of transformation of arsenic in the environment and their effect on arsenic toxicity (speciation).

4. Testing for Arsenic On Site-to evaluate field test kits in terms of sensitivity, reliability, applicability, and cost.

5. Remediation Technologies and Disposal of Residues-to assess technologies according to type of water treated: potable water, irrigation water, environmental water, and wastewater.

6. Case Studies-to present a collection of representative case studies reported by members of the task group.

7. Summary Recommendations-to provide a decision-making system, supported by information flow from the above aspects.

References

1. www.epa.gov/safewater/ars/arsenic_finalrule.html

2. D.H. Caussy, The Arsenic Catastrophe in India and Bangladesh-Can it be Solved? Special seminar report. LSHTM August 2003.

3. P.L. Smedley and D.G. Kinniburgh, Appl. Geochem. 17(5), 517-568 (2002).

For more information and comments, contact the Task Group Chairman Hemda Garelick <h.garelick@mdx.ac.uk>.

www.iupac.org/projects/2003/2003-017-2-600.html 